\title{
Evaluation of different sample introduction approaches for the determination of boron in unalloyed steels by inductively coupled plasma mass spectrometry
}

\author{
A.G. Coedo*, M.T. Dorado, I. Padilla \\ CENIM (CSIC), Gregorio del Amo 8, 28040 Madrid, Spain
}

Received 23 June 2004; accepted 28 October 2004

Available online 30 November 2004

\begin{abstract}
An extended study of different sampling introduction approaches using inductively coupled plasma mass spectrometry (ICP-MS) is presented for the determination of boron in steel samples. The following systems for sample introduction were applied: direct sample solution nebulization by continuous nebulization $(\mathrm{CN})$ using a cross-flow nebulizer and with flow injection (FI), applied to $0.1 \%$ (m/v) and $0.5 \%$ $(\mathrm{m} / \mathrm{v})$ sample solutions, respectively; FI after iron matrix extraction, using acetylacetone-chloroform, and isotopic dilution (ID) analysis as the calibration method; FI with on-line electrolytic matrix separation; and spark ablation (SA) and laser ablation (LA) as solid sampling techniques. External calibration with matrix-matching samples was used with CN, SA, and LA, and only acid solutions (without matrix matching) with FI methods. When FI was directly applied to a sample solution, the detection limit was of $0.15 \mu \mathrm{g} \mathrm{g}^{-1}$, improving by a factor of 4 that was obtained from the $\mathrm{CN}$ measurements. Isotopic dilution analysis, after matrix removal by solvent extraction, made it possible to analyse boron with a detection limit of $0.02 \mu \mathrm{g} \mathrm{g}^{-1}$ and, with the on-line electrolytic process, the detection limit was of $0.05 \mu \mathrm{g} \mathrm{g}^{-1}$. The precision for concentrations above 10 times the detection limit was better than $2 \%$ for CN, as well as for FI methods. Spark and laser ablation sampling systems, avoiding digestion and sample preparation procedures, provided detection limits at the $\mu \mathrm{g}^{-1}$ levels, with RSD values better than $6 \%$ in both cases. Certified Reference Materials with B contents in the range $0.5-118 \mu \mathrm{g} \mathrm{g}^{-1}$ were used for validation, finding a good agreement between certified and calculated values.
\end{abstract}

(C) 2004 Elsevier B.V. All rights reserved.

Keywords: Inductively coupled plasma mass spectrometry; Sampling systems; Steels analysis; Boron determination

\section{Introduction}

The boron content in steels influences the technological properties of the material. Very low concentrations of boron have an important effect on hardenability, creep resistance, hot workability, etc. Compared with most other allowing elements, the amount of boron added to the steel is extremely small, and commonly, the boron content in boron-treated carbon steels ranges from $0.0005 \%$ of less to about $0.005 \%$ (too little boron may be ineffective, and too much can cause difficulties in rolling or forging; [1]).

\footnotetext{
* Corresponding author. Tel.: +34 91 5538900; fax: +34 915347425

E-mail address: coedo@cenim.csic.es (A.G. Coedo).
}

Therefore, the boron determination in steels must be both precise and accurate. Since the first introduction of an inductively coupled plasma mass spectrometer (ICP-MS) on the market, the merits of this analytical technique have been intensively studied. The technique has excellent detection limits for trace elements determination [2]; however, matrix effects (e.g., signal suppression) may be important [3]. As the low mass number elements are more affected than the heavier ones, the suppression effect for boron is very important and seriously reduces detection power [4].

When using sample dissolution, conventional digestion procedures may yield results that are either imprecise or inaccurate due to a chemical resistance of boron compounds (nitrides, etc.) and the possible loss of boron 
during the acid attack, even at the ambient temperature. Furthermore, the large amounts of reagents needed cause contamination, and high salt and acid concentrations result in interference effects in the sample introduction system (interface of ICP-MS). The microwave digestion technique offers a very effective and fast dissolution system in addition to low contamination values. The digestion efficiency depends upon the sample solution temperature; this corresponds to the demand for higher temperature of the digestion solution for decomposing and dissolving boron nitrides [5].

In ICP-MS, matrix effects may be important, and it is generally accepted to limit analyte solutions to a total dissolved solids content nominally $<1-2 \mathrm{mg} \mathrm{ml}^{-1}$, when continuous nebulization $(\mathrm{CN})$ is used. This large solid to solution dilution factor causes deterioration in the limits of quantification. Many types of alternative sampling systems have been used with ICP-MS for maximizing accuracy and for improving the analytical figures of merit, such as sensitivity and determination limit. Some of these approaches have experienced a wide level of acceptance, such as flow injection (FI) methods. Others tend towards on/off-line preconcentration procedures or solid sampling systems, such as spark and laser ablation (SA and LA, respectively). Flow injection methodology offers a number of advantages for the analysis of samples with a high matrix concentration [6]. In FI sample, volumes are typically on the order of a few hundred microliters, and this factor is effective in minimizing the effects of matrix deposition on the sampling cone aperture that are produced in steady-state analysis $(\mathrm{CN})$. To achieve the determination of boron in steel samples in the low $\mathrm{ng} \mathrm{g}^{-1}$ range, the use of measurement solutions with a large sample/volume proportion is required. The separation of the analyte from the matrix is the most radical way to avoid suppression problems. Solvent extraction is one of the systems that can be applied, and the use of acetylacetone for iron separation is one of the most effective [7]. To minimize the effects of the total salt concentration resulting from the acetylacetone matrix extraction process and to improve accuracy and precision, FI [8,9] and ID [10-12] can be applied for ICPMS sampling and measurements. Nevertheless, the most satisfactory method for the complete separation of large amounts of iron in a single operation is one in which the iron is electrolytically deposited on or in a mercury cathode in diluted sulphuric acid solution [13]. With a view to avoiding the sample dissolution and pretreatment processes, interest has been growing in the use of direct solid sample introduction systems. Spark ablation and laser ablation have been applied as solid sampling techniques [14].

In spark ablation, the suitability of a variety of discharge types has been discussed [15]. The most important issues are optimizing and controlling the spark operating conditions (resistance, voltage, and repetition rate), to be able to introduce a representative sample amount, control the particle size, and maintain a constant sample uptake rate. As the plasma energy is only sufficient to dissociate and ionize a finite amount of material without unacceptable disturbance to the equilibrium, if the load is exceeded or if the solid particles are too large, undissociated material passes through the plasma and deposits on the sample cone orifice, resulting in a loss of sensitivity. To overcome this problem, restrictive paths have been designed to control the aerosol reaching the plasma [16]. For laser ablation, due to the small sample quantities that are removed, a high sensitivity is essential for trace and ultra trace analysis $[17,18]$. This made the combination of LA and ICP-MS an attractive and widespread solution [19].

In this paper, different sample introduction procedures were applied for the determination of B in steel samples, and their performance was tested by analysing Certified Reference Materials. Limits of detection (DL, estimated as three times the standard deviation of the signal obtained from a procedural blank), precision as RSD (estimated at concentrations levels of 10 times the DL, $n=6$ ), and application ranges (established on the basis of CRM disposability) were evaluated.

\section{Experimental}

\subsection{Apparatus, materials, and reagents}

An ELAN 6000 ICP-MS (Perkin Elmer SCIEX, Thornhill, Ontario, Canada) and the following sampling devices: FIAS-400 flow injection system (Bodenseewerk Perkin Elmer, Überlingen Germany), SPARK 10 (Varian Techtron, Mulgrave, Victoria, Australia), and LSX-100 Laser-Ablation (CETAC Technologies, Omaha, NE) were used. Microwave digestions of the steel samples were carried out using a Milestone MLS-1200 MEGA microwave oven, equipped with pressure (APC-30) and temperature control (ATC-300), and polyethylene high-pressure digestion vessels. Deionized water of $18 \mathrm{M} \Omega \mathrm{cm}^{-1}$, obtained from an ELGA MAXIMA ultra pure water system, and Suprapur brand reagents were used throughout.

High-purity iron (Johnson \& Mattey) was used for matrix matching and recovery tests. The Certified Reference Materials JSS 002/2 (from The Iron and Steel Institute of Japan, Tokio), Standard Reference Materials NIST 361 and 365 (National Institute of Standard and Technology, Gaithersburg, MD), CRMs 097-1, 098-1, and series 456/1-460/1 (from Bureau of Analysed Samples, Middlesbrough, England), with $\mathrm{B}$ contents in the range $0.5-118 \mu \mathrm{g} \mathrm{g}^{-1}$, were used for verification. Standard reference material SRM 951 from NIST, ${ }^{10} \mathrm{~B} /{ }^{11} \mathrm{~B}$ ratio of $0.2473\left({ }^{10} \mathrm{~B}=19.827 \%,{ }^{11} \mathrm{~B}=80.173 \%\right)$, and $\left({ }^{10} \mathrm{~B}\right)$ boric acid (a Sigma-Aldrich isotopically enriched biisotopic spike, 97 at. $\%{ }^{10} \mathrm{~B}$ ) were used for isotopic dilution (ID) analysis. 


\subsection{Sample solutions preparation}

The sample/acids proportions, as well as the oven heating program, were established by evaluating the efficiency of the dissolution procedure for the sample BCS-460/1. This CRM, with a certificate value for total boron of $28 \mu \mathrm{g} \mathrm{g}^{-1}$, contains a high proportion of nonsoluble boron particles (about $53 \%$ of the total boron content). Different microwave digestion programmes were applied, varying the operational parameters (microwave power and time; [20]). As a result of this study, the following operating dissolution procedure was adopted: $0.25 \mathrm{~g}$ of the test sample, weighed to the nearest $0.0001 \mathrm{~g}$, was dissolved in the microwave oven with the following acid mixture: $3.0 \mathrm{ml}$ of $\mathrm{HCl} 32 \%(\mathrm{~m} / \mathrm{v}), 1.0 \mathrm{ml}$ of $\mathrm{HNO}_{3}$ $70 \%(\mathrm{~m} / \mathrm{v}), 0.075 \mathrm{ml}$ of $\mathrm{HF} 48 \%(\mathrm{~m} / \mathrm{v})$, and $2 \mathrm{ml}$ of $\mathrm{H}_{2} \mathrm{SO}_{4}(1: 5 \mathrm{v} / \mathrm{v})$. The applied heating programme consisted of a two-stage power-time, with a preset temperature and pressure of $200{ }^{\circ} \mathrm{C}$ and 20 bar, respectively. The system was operated at $250 \mathrm{~W}$ unpulsed power for $5 \mathrm{~min}$, followed by a $15-\mathrm{min}$ pulsed step at $500 \mathrm{~W}$. The obtained solution was treated depending on the method to be applied. For direct $\mathrm{CN}$, the content was spiked with 12.5 $\mu \mathrm{g}$ of Be, used as internal standard (IS), and diluted to 250 $\mathrm{ml}$ (1 $\mathrm{mg}$ sample/ml of solution). For direct FI sampling, the content was spiked with $2.5 \mu \mathrm{g}$ of Be (IS) and made

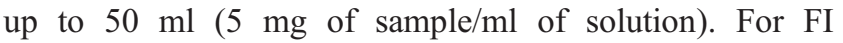
sampling, after iron matrix separation using acetylacetonechloroform and ID analysis as the calibration method, the sample treatment procedure is summarized in Fig. 1

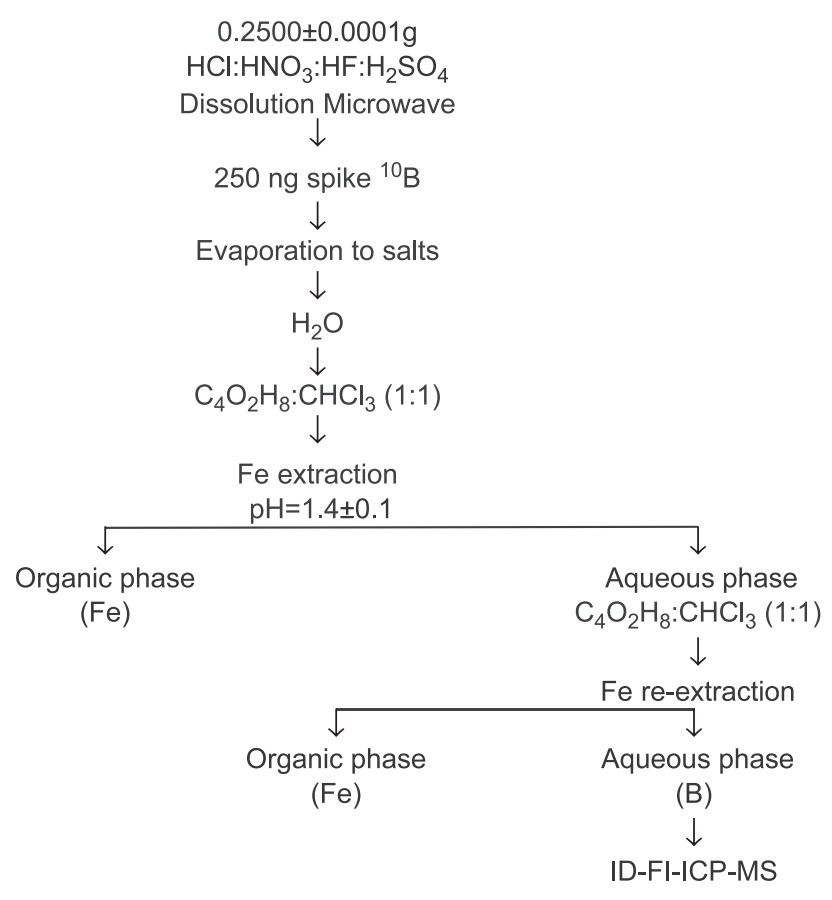

Fig. 1. Chemical procedure of test sample treatments for isotope dilution analysis. (measurement solution equivalent to $50 \mathrm{mg}$ of sample $/ \mathrm{ml}$ solution).

To apply the mercury cathode electrolysis, the microwave solutions were evaporated until white sulphuric acid fumes appeared, and the resulting salts were dissolved with $10 \mathrm{ml}$ of water. The solution was spiked with $1.25 \mu \mathrm{g}$ of Be (IS) and diluted to $25 \mathrm{ml}(10 \mathrm{mg}$ of sample/ml). The flow diagram of the manifold for the on-line process has been presented in a previous paper [13].

For spark and laser ablation sampling introduction systems, the samples in a disc-shaped form were finished to a clean uniform surface by using a surface grinder, with a 60 -grit abrasive finer zirconium oxide belt in an abrading device, rinsing with deionised water and acetone and drying with compressed air. In parallel with each one of the wet methods and following the same procedure, blank tests using the same quantities of all the reagents were carried out.

\section{Results and discussion}

\subsection{Direct solution nebulization (CN and FI)}

When $\mathrm{CN}$ was used, the microwave solutions $(0.1 \% \mathrm{~m} / \mathrm{v})$ were directly measured. A signal depression caused by total salt concentration was observed. The optimization of the ICP operating parameters (Ar flow rate and power) did not compensate for this depression, as the use of iron and acid matrix matched standard samples for quantification was necessary. The use of FI makes it possible for discrete sample volumes with higher dissolved solid contents $(0.5 \%$ $\mathrm{m} / \mathrm{v}$ ) to be introduced into the nebulization system, effectively helping to minimize matrix effects. The most important parameters in FI, which are injection volume, dispersion, and sample delivery rate, were optimized. The injection volume selected for the sample loop was $200 \mu \mathrm{l}$, providing a dispersion coefficient value $(D)$ of approximately 0.80 .

ICP parameters (nebulizer Ar flow and power) were also optimized. Fig. 2 compares the produced variations in the peak area measurements of a solution of $50 \mathrm{ng}$ $\mathrm{ml}^{-1} \mathrm{~B}$ in a $0.1 \% \mathrm{HNO}_{3}(\mathrm{v} / \mathrm{v})$ medium and in the presence of $0.5 \%(\mathrm{~m} / \mathrm{v}) \mathrm{Fe}$, applying nebulization flows of 1.0 and $1.11 \mathrm{~min}^{-1}$ at different ICP power values (1000-1300 w).

As can be observed, a nebulization flow rate of 1.11 $\min ^{-1}$ always produced the best sensitivity, whereas a nebulization flow of $1.01 \mathrm{~min}^{-1}$ showed lower sensitivity, compensating for the matrix influence, provided that an ICP power higher than $1200 \mathrm{~W}$ was applied. With all that in mind, the parameters selected were $1200 \mathrm{~W}$ of power and a $1.01 \mathrm{~min}^{-1}$ of nebulization flow rate; under these conditions, it is not necessary to prepare the calibration samples in the presence of the iron matrix. The experimental recoveries from a $0.5 \% \mathrm{~m} / \mathrm{v}$ Fe matrix solution compared 


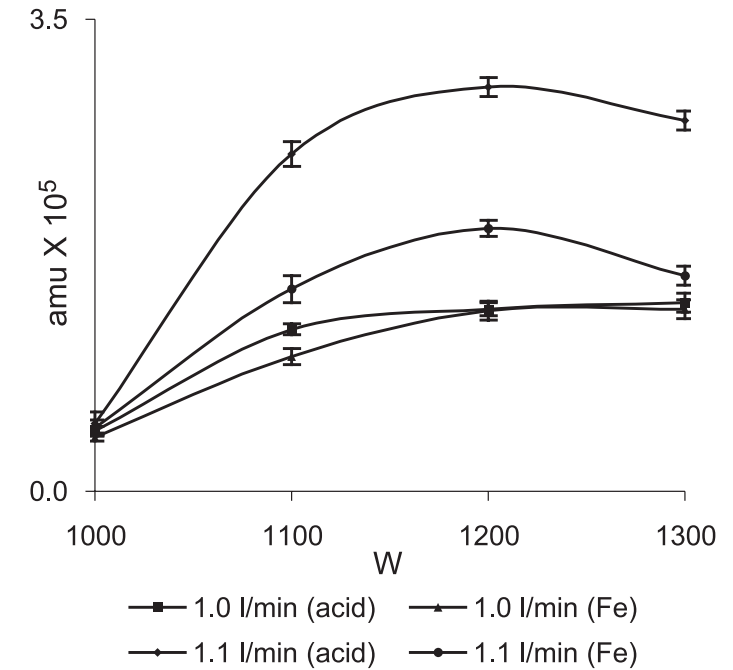

Fig. 2. Effect of power on $50 \mathrm{ng} \mathrm{ml}^{-1}$ Boron signal, using 1.0 and 1.1 $1 \mathrm{~min}^{-1}$ nebulizer gas flows, in $0.1 \% \mathrm{v} / \mathrm{v} \mathrm{HNO}_{3}$ and in the presence of $0.5 \% \mathrm{~m} / \mathrm{v} \mathrm{Fe}$.

with $0.1 \% \mathrm{~m} / \mathrm{v} \mathrm{HNO}_{3}$ solution were better than $98 \%$. In both methods, $\mathrm{CN}$ and FI, to compensate for signal fluctuations and instrument drift, the internal standard (IS) technique, based on intensity ratios with respect to a fixed concentration of spiked IS element, was used. In view of the fact that signal suppression was established to be mass number and ionization potential (IP) dependent, ${ }^{9} \mathrm{Be}(\mathrm{IP}=9.3 \mathrm{eV})$ was selected as IS for ${ }^{11} \mathrm{~B}(\mathrm{IP}=8.3 \mathrm{eV})$ measurements. Be is suitable for this purpose mainly because of the very low levels at which it is present in steel samples and also because its second ionization potential $(\mathrm{IP}=18.0 \mathrm{eV})$ is higher than the first ionization potential of the $\mathrm{Ar}(\mathrm{IP}=15.7 \mathrm{eV})$ plasma.

\subsection{Isotope dilution analysis after extraction matrix removal}

The most satisfactory method to overcome the matrix effect may be to separate the analyte from the matrix, as, in this case, the matrix may be totally removed, with the additional benefit of analyte concentration. A 1:1 mixture of acetylacetone and chloroform was chosen as an extraction reagent. As the percentage of metal ion extracted is principally a function of the $\mathrm{pH}$ and of the oxidation state of the metal ion, tests were carried out to optimize the $\mathrm{pH}$ value. The data produced indicate that $1.3-1.5$ is the optimal $\mathrm{pH}$ range; at $\mathrm{pH}$ values below 1.3 , iron extraction is not quantitative, and at $\mathrm{pH}$ values of more than 1.5, iron hydroxide precipitation takes place. Consequently, the extraction process was carried out at a continuously controlled $\mathrm{pH} 1.4 \pm 0.1$. After iron matrix separation, the source of salt concentration in the test solutions resulted from the $\mathrm{H}_{2} \mathrm{SO}_{4}$ added in the acid digestion step and from the $\mathrm{NH}_{4} \mathrm{OH}$ used to adjust the $\mathrm{pH}$. The signals from light analytes show a high suppression in a $0.5 \mathrm{~mol} \mathrm{l}^{-1} \mathrm{H}_{2} \mathrm{SO}_{4}$ matrix compared with a 0.14 mol $1^{-1} \mathrm{HNO}_{3}$ matrix. To minimize the problem, flow injection was used as a microsampling system. The boron signal depression, caused by the salt concentration resulting from the iron extraction process, was still observed during microsampling. To overcome this problem, the ID technique was applied. By altering the natural ratio between two isotopes in the sample, adding an accurately known quantity of an isotopic spike, and measuring the ratio of the mixture, the concentration of analyte present in the test sample can be deduced according to the general equation:

$C=\left[K M_{\mathrm{s}}\left(A_{\mathrm{s}}-R B_{\mathrm{s}}\right)\right] /[W(R B-A)]$

Where $K$ is the ratio of the natural atomic weight and the atomic weight of the enriched material, $M_{\mathrm{s}}$ is the mass of the spike, $W$ is the weight of the sample, $A$ and $B$ are the natural isotopic abundances of both isotopes, $A_{\mathrm{s}}$ and $B_{\mathrm{s}}$ are the isotopic abundances of both isotopes in the spike, and $R$ is the measured isotope ratio of the mixture of the sample and the spike. Fig. 1 summarized the applied sample preparation procedure. A "procedural" blank was used to correct for interferences that occur as a result of the reagents used for sample preparation, for contamination and, in addition, for plasma background species due to solvent and the argon ICP.

\subsection{Electrolysis for matrix separation using a minidevice}

The mercury cathode electrolytic system was optimized off-line in a mini-Hg cathode electrolysis cell [21] using a high current density $>0.2 \mathrm{~A} \mathrm{~cm}^{-2}$. After optimization, the methodology was transferred to the on-line FI system, inserting a microcell in the manifold. A careful evaluation of the microcell dimensions led to the conclusion that a good compromise between electrolysis speed and ease in draining can be achieved using an electrolytic microcell [13] with a mercury cathode area of approximately $5 \mathrm{~cm}^{2}(1 \mathrm{~cm}$ in width and $5 \mathrm{~cm}$ in length) and $2 \mathrm{~cm}$ high, with a 2-mm-diameter platinum wire anode, and a cathode anode separation of $0.5 \mathrm{~cm}$. Table 1 shows the working conditions used to perform the FI analysis.

Table 1

Working parameters used to perform the FI analysis

\begin{tabular}{ll}
\hline Sample solution & $0.250 \mathrm{~g}$ in $25 \mathrm{ml}$ \\
Aliquot electrolysed & $3 \mathrm{ml}$ \\
Electrolysis medium & $0.3 \mathrm{~mol} \mathrm{l}^{-1} \mathrm{H}_{2} \mathrm{SO}_{4}$ \\
Carrier and washing solution & $0.5 \% \mathrm{v} / \mathrm{v} \mathrm{HNO}$ \\
Loop volume & $200 \mu 1$ \\
Calibration samples & $0.3 \mathrm{~mol} \mathrm{l}^{-1} \mathrm{H}_{2} \mathrm{SO}_{4}$ boron \\
& standard solutions \\
Circulating Hg speed & $14 \mathrm{ml} \mathrm{min}^{-1}$ \\
Carrier flow rate & $3.5 \mathrm{ml} \mathrm{min}$ \\
\hline
\end{tabular}


After matrix separation by electrolysis, the only source of matrix interferences due to the sample composition and the sample preparation procedure resulted from the $\mathrm{H}_{2} \mathrm{SO}_{4}$ concentration present in the electrolyte $\left(0.3 \mathrm{~mol} \mathrm{l}^{-1} \mathrm{H}_{2} \mathrm{SO}_{4}\right)$. The signals for Boron are greatly suppressed in an $\mathrm{H}_{2} \mathrm{SO}_{4}$ media compared with an $\mathrm{HNO}_{3}$ media of the same molarity. To overcome and compensate for this influence, $0.3 \mathrm{~mol}^{-1}$ $\mathrm{H}_{2} \mathrm{SO}_{4}$ standard boron solutions were used for external calibration.

\subsection{Solid sampling systems (SA and LA)}

The two "ablation" techniques of solid sampling for ICPMS analysis, spark ablation and laser ablation, were applied. Both of them share important similarities in that material is ablated from a sample in a cell, using either an electrical discharge or a focused pulsed laser. A significant fraction of the ablated material is carried in a continuous flow of argon to the ICP, where it is converted into ions for quantification. Important differences exist, however, between the two techniques, notably in the greater flexibility of laser sampling and, most importantly, the ability to focus and direct a laser precisely, thereby creating a microprobe technique, with the capability of spatially resolved sampling. This ability makes necessary the use of very homogeneous samples for having a good precision when the system is to be used for bulk analysis.

The spark device used [16] was developed for application in ICP-AES, and to be applied in ICP-MS, some modifications had to be made to minimize the mass of eroded material reaching the plasma along an entire sampling sequence (prespark, read time delay, and measurement), thus minimizing the risk of cone blockage and drift effects. To satisfy this necessity, two main modifications were introduced: insertion of a valve system (to allow the gas stream with the eroded material to be diverted to waste, during presparking, and only during analysis does the sample reach the plasma) and a restrictive path. Because of the high sensitivity of the ICP-MS technique and its low tolerance to the size and quantity of the particles reaching the plasma, the restrictive path was designed to maintain a good sensitivity and minimize solid deposition at the injector and the cone orifices. Three cyclones, used as restrictive devices, were installed in series just after the spark chamber; these devices operate by imparting a spiral motion to the aerosol, as a result of which, owing to the higher angular momentum, particles of large diameter tend to impact on the walls of the chamber and, therefore, do not reach the plasma. Control of the aerosol particle size by the cyclones leads to a more uniform particle size distribution, thereby improving the precision of measurements and preventing the deposition of material on the sampling cones. The effectiveness of the complete restrictive device in removing large eroded particles from the Ar stream was evaluated by trapping the particles during fixed periods of 5 min in $5 \%(1+3) \mathrm{HCl}-\mathrm{HNO}_{3}$ and comparing the Fe content before and after the restrictive path. This efficiency was found to be approximately of one order of magnitude (from about 10 to $1.0 \mu \mathrm{g} \mathrm{min}{ }^{-1}$ ).

Fig. 3 shows the cyclone device designed. Sparking operating conditions were optimized by applying different combinations of frequency (from 200 to $1000 \mathrm{~Hz}$ ) and current (from 20 to 60 A) to sample BCS 459/1 (0.0118\% B). From the values obtained, and taking into consideration the need for both a good sensitivity and a satisfactory stability, the selected electrical operating parameters were $500 \mathrm{~Hz}$ and $60 \mathrm{~A}$.

In the laser ablation system, the sample is sealed in an ablation chamber, where it is irradiated by a laser under flowing Ar carrier gas.

The optimization of the laser operating parameters was performed using a CRM sample of carbon steel, residual elements: BCS $459 / 1(0.0118 \%$ B). The influence of laser energy output and of pulse repetition rate was determined, with consideration for the ion intensities of both boron and Fe matrix. Tests were conducted by applying 100 laser pulses to a fixed location on the sample. The best results (high sensitivity and low RSD values) were obtained when working with the highest laser power energy and pulse repetition rate provided by the laser module ( $3 \mathrm{~mJ}$ and $20 \mathrm{~Hz})$.

Calibration is one of the most important aspects of the ablation sampling devices, and it is a limiting factor for quantitative analysis. External calibration utilizing matrix-

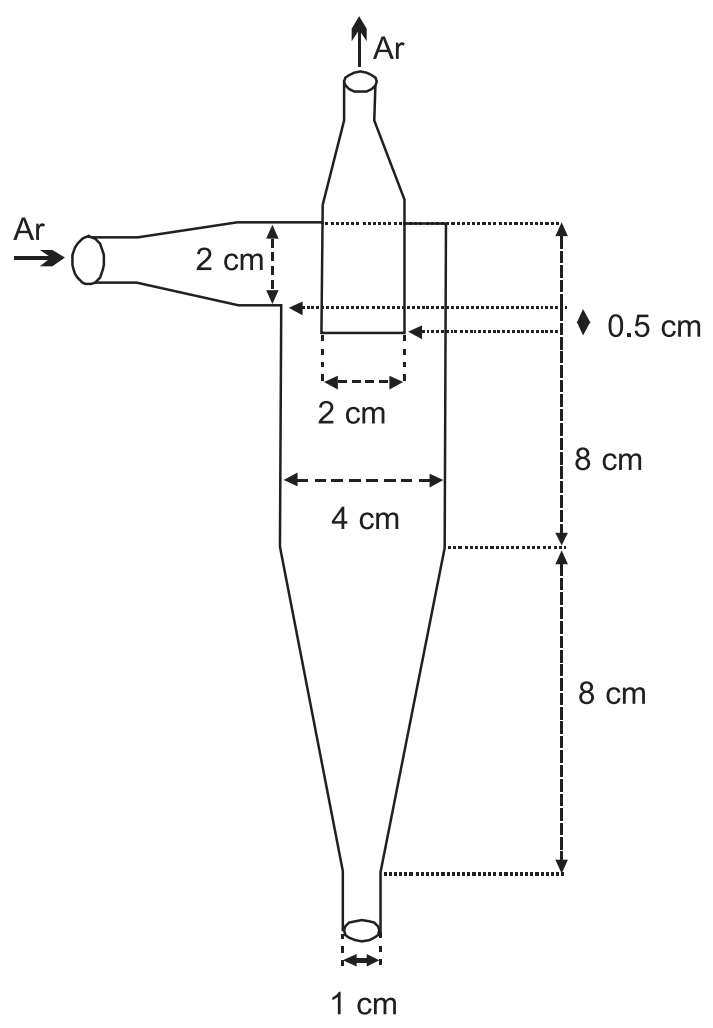

Fig. 3. Cyclone device. 
Table 2

Figures of merit of the developed methods

\begin{tabular}{llll}
\hline $\begin{array}{l}\text { Method (sample proportion } \\
\text { in the test solutions) }\end{array}$ & $\begin{array}{l}\mathrm{DL}(3 \mathrm{~s}) \\
{\left[\mu \mathrm{g} \mathrm{g} \mathrm{g}^{-1}\right]}\end{array}$ & $\begin{array}{l}\mathrm{RSD}(n=6) \\
\end{array}$ & $\begin{array}{l}\text { Application } \\
\text { range }\left[\mu \mathrm{g}^{-1}\right]\end{array}$ \\
\hline $\mathrm{CN}(0.1 \% \mathrm{~m} / \mathrm{v})$ & 0.6 & 1.2 & $2.8-28$ \\
$\mathrm{FI}(0.5 \% \mathrm{~m} / \mathrm{v})$ & 0.2 & 1.4 & $0.5-28$ \\
$\mathrm{ID}$ matrix removal $(5 \% \mathrm{~m} / \mathrm{V})$ & 0.02 & 0.8 & $0.5-28$ \\
FI-electrolysis $(1 \% \mathrm{~m} / \mathrm{V})$ & 0.05 & 1.9 & $1.0-28$ \\
SA (solid samples) & 2.1 & 3.8 & $15-118$ \\
LA (solid samples) & 3.0 & 5.0 & $15-118$ \\
\hline
\end{tabular}

matched standards is the most common quantification method in SA and LA. Matrix matching is important because the ablation yield varies with the sample matrix. A reference to compensate for changes in the quantity of mass ablated and drift effects is generally required. Relative intensities were rationed to the ${ }^{57} \mathrm{Fe}$ isotope (abundance $=2.19 \%$ ). The Certified Reference Materials SS-456/ 1 to SS-460/1 (carbon steels and residual series) and the BAM CRM 098-1 (pure iron) were used to perform the calibration graphs.

\subsection{Analytical figures of merit and analysis results}

The analytical figures of merit of the developed methods were compared. The detection limits were calculated on the basis of the standard deviation of six successive measurements of a procedural blank solution, using the criterion $3 \mathrm{~s}$. Precision was evaluated from the solutions prepared with the same reagents and under the same conditions as the test samples, at concentration levels of 10 times the DL. The verified application ranges were established on the basis of the disposable certified reference materials. Table 2 shows these values comparatively.

The described methods from dissolved samples $(3.1,3.2$, and 3.3) were verified by analysing the same CRM samples. Table 3 shows the correlation between the certified and found values for the described methods.

In solid samples, after verifying the linearity of the intensity ratio versus analyte concentrations (using all the samples: BCS-SS 456/1-460/1 and pure iron CRM 098-1),
Table 4

Certified and found values ( $n=6$ ) for CRMs SS $456 / 1$ to $460 / 1$, from solid samples

\begin{tabular}{llll}
\hline CRM & \multicolumn{3}{l}{ Boron contents $\left[\mu \mathrm{g} \mathrm{g}^{-1}\right]($ S.D. $)$} \\
\cline { 2 - 4 } & Certified & SA & LA \\
\hline $098-1$ & $<1$ & Low $^{\mathrm{a}}$ & Low $^{\mathrm{a}}$ \\
$456 / 1$ & $15(2)$ & $15(3)$ & $17(5)$ \\
$457 / 1$ & $25(2)$ & $24(7)$ & $28(5)$ \\
$458 / 1$ & $61(2)$ & $65(4)$ & $64(6)$ \\
$459 / 1$ & $118(5)$ & $\mathrm{High}^{\mathrm{a}}$ & High $^{\mathrm{a}}$ \\
$460 / 1$ & $28(2)$ & $30(4)$ & $26(3)$ \\
\hline a &
\end{tabular}

${ }^{\mathrm{a}}$ Low and high samples used for calibration.

only two were employed for calibration, i.e., "low" and "high". The CRM 098-1 (pure iron) was used as the low standard, and the BCS CRM carbon steel 459/1, with the highest boron content, as the high standard. The remainder of the samples were analysed as unknowns. Table 4 lists these data, showing that a good agreement was found between the certified values and the obtained results.

By applying the $t$-test to the results obtained with the various developed methods, no significant differences at the $95 \%$ probability level were found.

From the obtained results, it can be concluded that, among all the tested methods, the most precise and sensitive is the ID analysis after matrix separation with acetylacetone-chloroform. The remaining methods, utilizing dissolved samples, show comparative RSD values $(\leq 2 \%)$, presenting big differences in the detection limits, being the determination after electrolytic matrix separation the most sensitive, followed by direct FI and by $\mathrm{CN}$. The solid sampling methods are less precise and sensitive than the wet methods are; nevertheless, they present the advantage of eliminating the sample pretreatment processes.

\section{Acknowledgments}

This work was carried out with financial support from the European Community for Steel and Carbon (ECSC) and from the Commisión Interministerial de Ciencia y Tecnología (CICYT).

Table 3

Certified values and found results $\left(\mu \mathrm{g} \mathrm{g}^{-1} ; n=3\right)$ for the CRM analysed samples, from solutions

\begin{tabular}{|c|c|c|c|c|c|}
\hline \multirow[t]{2}{*}{ Sample } & \multirow[t]{2}{*}{ Certified (s) } & \multicolumn{2}{|c|}{ Direct solution nebulization } & \multicolumn{2}{|c|}{ Matrix separation $^{\mathrm{a}}$} \\
\hline & & $\mathrm{CN}$ & FI & Sol. ext. (ID) & Online electrol \\
\hline JSS 002-2 & 0.5 & $<2^{b}$ & $0.51(0.02)$ & $0.49(0.01)$ & $0.51(0.02)$ \\
\hline SRM 365 & 1.3 & $<2^{\mathrm{b}}$ & $1.54(0.04)$ & $1.35(0.02)$ & $1.4(0.1)$ \\
\hline BAS 097-1 & $3(1)$ & $2.8(0.1)$ & $2.84(0.05)$ & $2.54(0.05)$ & $2.8(0.1)$ \\
\hline SRM 361 & 3.7 & $4.1(0.2)$ & $3.9(0.1)$ & $4.18(0.05)$ & $4.1(0.2)$ \\
\hline CRM 456/1 & $15(2)$ & $14.7(0.2)$ & $16.5(0.2)$ & $15.36(0.11)$ & $15.1(0.2)$ \\
\hline CRM 457/1 & $25(2)$ & $24.5(0.3)$ & $26.6(0.2)$ & $25.50(0.15)$ & $25.7(0.4)$ \\
\hline CRM 460/1 & $28(2)$ & $29.1(0.2)$ & $27.0(0.3)$ & $27.32(0.16)$ & $28.2(0.4)$ \\
\hline CRM 458/1 & $61(2)$ & $61.2(0.8)$ & $63.0(0.4)$ & - & - $\quad$ r \\
\hline CRM 459/1 & $118(5)$ & $118(2)$ & $120(1)$ & - & - \\
\hline
\end{tabular}

${ }^{\mathrm{a}}$ Matrix separation was only applied for B contents $<30 \mathrm{ppm}$.

${ }^{b} \mathrm{LOQ}=$ limit of quantification, calculated as the concentration that gives a signal equal to 10 times the S.D. of the blank (high-purity iron). 


\section{References}

[1] K.E. Thelning, Steel and its Heat Treatment, in: K.E. Thelning (Ed.), Butterworth, London, 1984.

[2] K.E. Jarvis, A.L. Gray, R.S. Houk, Handbook of Inductively Coupled Plasma Mass Spectrometry, Blackie \& Son, London, 1992.

[3] C. Vandecasteele, M. Nagels, H. Vanhoe, R. Dams, Suppression of analyte signal in inductively-coupled plasma/mass spectrometry and the use of an internal standard, Anal. Chim. Acta 211 (1988) 91-98.

[4] H. Ekstroem, I. Gustavsson, Applications of Plasma Source Mass Spectrometry II, in: G. Holland, A.N. Eaton (Ed.), Royal Society of Chemistry, Cambridge, 1993, pp. 150-157.

[5] H.-M. Kuss, D. Bossmann, M. Müller, Progress of analytical chemistry in the iron and steel industry, in: R. Nauche (Ed.), Commission of the European Communities, Luxembourg, 1992, p. 302.

[6] R.C. Hutton, A.N. Eaton, Analysis of solutions containing high levels of dissolved solids by inductively coupled plasma mass spectrometry, J. Anal. At. Spectrom. 3 (1988) 547-550.

[7] J. McKaveney, H. Freiser, Analytical solvent extraction of molybdenum using acetylacetone, Anal. Chem. 29 (1957) 290-292.

[8] A. Stroh, U. Voellkoph, E.R. Denoyer, Analysis of samples containing large amounts of dissolved solids using micro-sampling flow-injection inductively coupled plasma mass spectrometry, J. Anal. At. Spectrom. 7 (1992) $1201-1205$.

[9] P. Richner, Detection limits versus matrix effects: analysis of solutions with high amounts of dissolved solids by flow-injection inductively coupled plasma mass spectrometry, J. Anal. At. Spectrom. 8 (1993) 927-931.

[10] H.P. Longerich, Application of isotope dilution to inductively coupled plasma mass spectrometry, At. Spectr. 10 (4) (1989) 112-115.

[11] A. Makishima, I. Inamoto, K. Chiba, Determination of gallium in pure aluminium by isotope-dilution analysis with solvent extraction using inductively coupled plasma mass spectrometry, Appl. Spectrosc. 44 (1) (1990) 91-95.

[12] A.G. Coedo, T. Dorado, B.J. Fernández, F.J. Alguacil, Isotope dilution analysis for flow injection ICPMS determination of microgram per gram levels of boron in iron and steel after matrix removal, Anal. Chem. 68 (1996) 991-996.
[13] A.G. Coedo, I. Padilla, T. Dorado, F.J. Alguacil, A micro-scale mercury cathode electrolysis procedure for on-line flow injection inductively coupled plasma mass spectrometry trace elements analysis in steel samples, Anal. Chim. Acta 389 (1999) 247-255.

[14] D. Günther, S.E. Jackson, H.P. Longerich, Laser ablation and arc/ spark solid sample introduction into inductively coupled plasma mass spectrometers, Spectrochim. Acta Part B 54 (1999) 381-409.

[15] A.G. Coedo, T. Dorado, B.J. Fernández, Spark ablation as sampling device for inductively coupled plasma mass spectrometric analysis of low-alloyed steels, J. Anal. At. Spectrom. 10 (1995) 859-863.

[16] R. Maibusch, H.-M. Kuss, A.G. Coedo, T. Dorado, I. Padilla, Spark ablation inductively coupled plasma mass spectrometry analysis of minor and trace elements in low and high alloy steels using single calibration curves, J. Anal. At. Spectrom. 14 (1999) 1155-1162.

[17] I. Rodushkin, M.D. Axelsson, D. Malinovsky, D.C. Baxter, Analyteand matrix-dependent elemental response variations in laser ablation inductively coupled plasma mass spectrometry, J. Anal. At. Spectrom. 17 (2002) $1223-1230$

[18] I. Rodushkin, M.D. Axelsson, D. Malinovsky, D.C. Baxter, Analyte- and matrix-dependent elemental response variations in laser ablation inductively coupled plasma mass spectrometry: Part 2. Implications for multi-element analyses, J. Anal. At. Spectrom. 17 (2002) 1231-1239.

[19] D. Günther, I. Horn, B. Hattendorf, Recent trends and developments in laser ablation-ICP-mass spectrometry, Fresenius' J. Anal. Chem. 368 (2000) 4-14.

[20] T. Dorado López, M. Del Monte, R. Falciani, A. Tamba, Application of a microwave oven as an objective, safe and rapid system for the dissolution and treatment of samples in the chemical analysis of iron and steel and related materials, Ed. Commission of the European Communities, CECA-EUR 15503 en, ISNB 92-827-5250-X, Luxembourg, 1996.

[21] A.G. Coedo, T. Dorado, I. Padilla, F.J. Alguacil, Study of the application of air-water flow injection inductively coupled plasma mass spectrometry for the determination of calcium in steels, J. Anal. At. Spectrom. 11 (1996) 1037-1041. 